\title{
FREUD E A TEORIA DA ELABORAÇÃO DOS SONHOS: INVESTIGAÇÕES À LUZ DA FILOSOFIA DE MARTIN HEIDEGGER E DE PAUL RICOEUR
}

\author{
Fernanda De Jesus Almeida ${ }^{1}$ \\ Caroline Vasconcelos Ribeiro ${ }^{2}$
}

RESUMO: Com esse artigo almejamos estabelecer uma discussão acerca da cientificidade da psicanálise de Freud, tendo como horizonte de questionamentos a maneira como Freud teoriza sobre a interpretação dos sonhos. Pleiteamos investigar se o pensamento freudiano se afina com as ciências naturais, como advoga o filósofo Martin Heidegger, ou se, devido ao fato de preconizar a decifração de sentidos dos conteúdos oníricos, se afasta do naturalismo, como afirma Paul Ricoeur. Na obra "Seminários de Zollikon", Heidegger assegura que a psicanálise freudiana se encaixa no rol das ciências da natureza e que o conceito de inconsciente está a favor da explicabilidade do psiquismo, do estabelecimento de leis e causas que regem o seu funcionamento. Nessa perspectiva, a concepção de sonho 
como um produto da ação do inconsciente afinar-se-ia com a pretensão de explicabilidade causal, típica das ciências da natureza. Já Paul Ricoeur, na obra "Da interpretação: um ensaio sobre Freud", defende que não se pode entender que decifração dos sentidos dos sonhos consista em um procedimento puramente naturalista. Sendo assim, para Ricoeur, com a teoria acerca da formação dos sonhos, Freud amenizou a influência naturalista que marcou o início de suas pesquisas. Pretendemos; com esse artigo; analisar se, ao interpretar os sonhos, Freud estaria fazendo o exercício de compreensão dos fenômenos, típico das Ciências do Espírito, ou se, como atesta Heidegger, estaria em busca de um tipo de explicabilidade afinado com a Ciência da Natureza.

PALAVRAS-CHAVE: Freud; Heidegger; Interretação dos sonhos; Ricoeur.

ABSTRACT: With this article we aim to establish a discussion about the scientific aspect of Freud's psychoanalysis, with the horizon of questioning the way Freud theorized about the interpretation of dreams. We sought to investigate whether the Freudian thought is identified with the natural sciences, as plead philosopher Martin Heidegger, or if, due to the fact advocating the decipherment of oneiric contents, departs from the 
naturalism, as stated Paul Ricoeur. In the work "Zollikon Seminars" Heidegger ensures that the Freudian psychoanalysis fits in the role of the sciences of nature and that the concept of the unconscious is in favor of the psyche explicability, the establishment of laws and causes that govern its operation. In this perspective, the concept of dream as a action product of the unconscious would identify with the typical causal explicability pretense of the natural sciences. Paul Ricoeur, in the book "The interpretation: an essay on Freud" argues that you can not understand that deciphering the meanings of dreams consists in a purely naturalistic procedure. Therefore, for Ricoeur, with the theory of the dreams formation, Freud softened the naturalistic influence that marked the beginning of their research. We intend with this article, to analyze, in interpreting dreams, Freud would be doing the exercise of understanding the typical phenomena of the Spirit Sciences or, as shown by Heidegger, would be looking for a kind of tuned explicability with the Nature of Science.

KEYWORDS: Freud; Heidegger; dreams interpretation: Ricoeur. 
Por meio de nossas investigações, pretendemos analisar a maneira como o filósofo alemão Martin Heidegger compreende a psicanálise desenvolvida por Sigmund Freud em contraponto com a perspectiva adotada pelo filósofo francês Paul Ricoeur fomentando, assim, um diálogo entre os dois enfoques teóricos. O posicionamento freudiano sobre as formações oníricas será nosso horizonte para essa discussão. As duas óticas citadas se diferem, pois, segundo Heidegger, a psicanálise freudiana serve-se de pressupostos naturalistas para apreender os fenômenos psíquicos, e, conforme Paul Ricoeur, Freud abandona esses pressupostos ao longo de suas obras, tendo iniciado o processo no célebre livro A Interpretação dos Sonhos (FREUD, 1996a). ${ }^{3}$ De acordo com os argumentos ricoeurianos, essa obra marca a inserção da psicanálise no campo da decifração onírica, portanto, traz consigo um discurso misto, no qual a interpretação se sobrepõe à lógica naturalista predominante nos escritos iniciais de Freud. Inicialmente visamos fazer uma descrição, ainda que sumária, de como Freud pensa a formação onírica e sua interpretação na obra em comento. Em seguida, pleiteamos explanar sobre o modo como Paul Ricoeur pensa a identidade da psicanálise freudiana, tendo como referência sua análise sobre a interpretação dos 
FREUD E A TEORIA DA ELABORAÇÃO DOS SONHOS...

sonhos. Apresentada essas abordagens, almejamos, por fim, examinar a posição de Heidegger frente à discussão.

\section{A INTERPRETAÇÃO DOS SONHOS SEGUNDO SIGMUND FREUD}

$\mathrm{Na}$ obra A Interpretação dos sonhos, Freud nos fornece um rico material de análises de sonhos, essas análises se articulam com o estabelecimento de teses gerais sobre a formação do material onírico, o que irá culminar em uma formulação sistemática acerca do funcionamento do aparelho psíquico. Essa obra apresenta uma concepção de um aparelho psíquico sem referências anatômicas, por conseguinte, os processos psíquicos que estariam presentes nesse aparelho prescindiriam de uma localização corpórea. Vejamos o que diz Freud:

Desprezarei por completo o fato de que o aparelho anímico em que estamos aqui interessados é-nos também conhecido sob a forma de uma preparação anatômica, e evitarei cuidadosamente a tentação de determinar essa localização psíquica como se fosse anatômica. Permanecerei no campo psicológico, e proponho simplesmente seguir a sugestão de visualizarmos o instrumento que executa nossas funções anímicas como semelhante a um microscópio composto, um aparelho fotográfico ou 
algo desse tipo. Com base nisso, a localização psíquica corresponderá a um ponto no interior do aparelho em que se produz um dos estágios preliminares da imagem. No microscópio e no telescópio, como sabemos, estes ocorrem, em parte, em pontos ideais, em regiões em que não se situa nenhum componente tangível do aparelho. (FREUD, 1996a, p.563)

Doravante, o aparelho psíquico é concebido "psicologicamente", sem base anatômica e composto por instâncias psíquicas e não mais por neurônios investidos, como na obra Projeto para uma psicologia científica (FREUD, 1996b). O aparelho psíquico passa a ter a natureza de uma especulação, ou seja, equivale a um constructo que não tem correspondência na empiria. Cabe ressaltar que o fato de não poder ser comprovado empiricamente; não torna esse conceito pouco importante ou infrutífero, afinal, é possível reconhecer o seu valor heurístico. Segundo Loparic (2001, p. 264), o uso de convenções heurísticas se deve ao seu valor metodológico, pois, podem ser usadas para organizar um fenômeno empiricamente. Tais convenções não têm valor de verdade, por isso podem ser modificadas ou descartadas, caso não sejam mais frutíferas. ${ }^{4}$ Freud, ao explicar ao leitor sobre o seu modo de abordar o funcionamento do aparelho psíquico, esclarece: 
FREUD E A TEORIA DA ELABORAÇÃO DOS SONHOS...

Retrataremos o aparelho psíquico como um instrumento composto a cujos componentes daremos o nome de "instâncias", ou (em prol de uma clareza maior) "sistemas". Pode-se prever, em seguida, que esses sistemas talvez mantenham entre si uma relação espacial constante, do mesmo modo que os vários sistemas de lentes de um telescópio se dispõem uns atrás dos outros. (FREUD, 1996a, p.563)

Apesar de não ser o alvo direto do presente trabalho, faremos, ainda que de maneira sumária, uma explanação sobre a subdivisão do aparelho psíquico e seu funcionamento. $\mathrm{Na}$ primeira topografia do seu aparelho psíquico, Freud nos fala em três instâncias: o consciente, pré-consciente e inconsciente. ${ }^{5}$

O consciente refere-se, segundo Freud (2004, p.83), apenas à representação que está presente em nossa consciência, ou seja, àquela que percebemos como tal. Já no inconsciente encontram-se os conteúdos latentes, aos quais não temos acesso direto e que fazem força para adentrar a consciência. É nessa instância que Freud localiza a mola geradora dos sonhos, chistes, lapsos e sintomas. Segundo o pai da psicanálise, “a força propulsora da formação dos sonhos é fornecida pelo inconsciente" (FREUD, 1996a, p. 
568). O inconsciente é visto como o fator causal destas formações psíquicas. Sobre a formação dos sintomas, Freud afirma que "o mundo interno do paciente histérico está recheado de representações psíquicas ativas, mas inconscientes; todos os seus sintomas originam-se delas" (FREUD, 2004, p.85). Continuando a definição das instâncias psíquicas, cabe indicar o pré-consciente, ou seja, a terceira instância onde se localiza uma censura ${ }^{6}$ que controla a passagem de conteúdos entre as demais localidades.

Entre as instâncias presentes na primeira topografia do aparelho psíquico, a de maior relevância para o desenvolvimento do tema relacionado ao nosso artigo é a instância inconsciente, pois é ela a responsável pelas formações oníricas. Freud (1996c, p.17) assinala que, devido à teorização da interpretação dos sonhos, a psicanálise progrediu em direção a uma ciência que não tinha os elementos conscientes como fundamentais. Ao passo que, na sua ciência a consciência é destituída da função causal em relação aos atos psíquicos, a sua teorização caminha em direção a uma psicologia profunda, baseada na análise de processos inconscientes. Ora, os sonhos são produtos do inconsciente, portanto, a teoria dos sonhos tem um papel essencial no desenvolvimento da psicanálise, pois foi a partir dela que se tornou possível a vinculação do inconsciente com processos da vida cotidiana, uma vez que 
FREUD E A TEORIA DA ELABORAÇÃO DOS SONHOS...

os sonhos acometem tanto pessoas sãs quanto doentes. Sendo assim, Freud ressalta:

Devamos voltar nossa atenção primeiramente para a posição que ocupa a teoria dos sonhos. Esta ocupa um lugar especial na história da psicanálise $\mathrm{e}$ assinala um ponto decisivo; foi com ela que a psicanálise progrediu de método psicoterapêutico para psicologia profunda. (FREUD, 1996c, p. 17)

O fato de conseguir dar inteligibilidade a um sonho, que inicialmente era nebuloso e não acessível, confirmava para Freud que sua ciência caminhava no rumo certo, no caminho da comprovação da existência do inconsciente. Mas, afinal de contas, como se forma o sonho? E quais as suas características? Para responder essas questões, recorremos a uma citação freudiana que nos elucida aspectos existentes nesse fenômeno da vida psíquica:

Nosso primeiro passo consiste em estabelecer nossa nova atitude para com o problema dos sonhos, introduzindo dois novos conceitos e nomes. O que tem sido chamado de sonho descrevemos como texto do sonho, ou sonho manifesto, e aquilo que estamos procurando, o que suspeitamos existir, por assim dizer, situado por trás do sonho, descreveremos como pensamentos oníricos latentes. 
Havendo feito isto, podemos expressar nossas duas tarefas conforme se segue. Temos de transformar o sonho manifesto em sonho latente, e explicar como, na mente do sonhador, o sonho latente se tornou sonho manifesto. A primeira parte é uma tarefa prática, pela qual é responsável a interpretação de sonho; exige uma técnica. A segunda parte é uma tarefa teórica, cuja atribuição é explicar a hipotética elaboração onírica; e só pode ser uma teoria. Ambas, a técnica de interpretação de sonhos e a teoria da elaboração onírica têm de ser recriadas. (FREUD, 1996c, p. 19-20)

Os sonhos são produto do inconsciente e, mesmo sendo imprecisos e aparentemente incoerentes, podem, com a ajuda do analista, ser transformados em um texto comunicável, assim, o que o analista procura estabelecer no relato do sonhador é a origem dos pensamentos latentes. Os sonhos manifestos, ou seja, o relato do sonhador pode ser das mais diversas características, desde um sonho coerentea sonhos que o sonhador não consegue distinguir com alguma precisão cenas ocorridas; daí a existência de uma técnica para que se possa chegar ao conhecimento do real motivo do sonho, ao seu conteúdo latente. Ainda sobre os sonhos, o criador da psicanálise dirá que se trata de uma realização distorcida do desejo. (FREUD, 1996a, p.560)

$\mathrm{Na}$ formação onírica, dois mecanismos assumem uma 
FREUD E A TEORIA DA ELABORAÇÃO DOS SONHOS...

posição privilegiada, são eles: condensação e deslocamento. A condensação se refere à tendência de formar novas unidades a partir de elementos que, em nossa vida de vigília, estariam separados. Sendo assim, Freud dirá que um elemento do sonho manifesto representa um grande número de pensamentos oníricos latentes- "como se fosse uma alusão conjunta a todos eles; e, em geral, o âmbito do sonho manifesto é extraordinariamente pequeno em comparação com a riqueza de material de que se originou" (FREUD, 1996d, p. 180). Quanto ao deslocamento, diz respeito à maneira como intensidades psíquicas são transferidas de um elemento para outro, sendo assim:

Com frequência acontece que um elemento que era de pequena importância nos pensamentos oníricos apareça como o aspecto mais claro, e, por conseguinte, mais importante do sonho manifesto e vice-versa, que elementos essenciais dos pensamentos oníricos sejam representados no sonho manifesto apenas por ligeiras alusões. (FREUD, 1996d, p. 180)

Segundo o pai da psicanálise, todos os processos envolvidos no trabalho do sonho só vieram à tona graças aos seus estudos, posto que antes os sonhos não correspondiam a um fenômeno psíquico cabível de uma 
explicação científica. Os dois mecanismos explanados acima se referem aos processos que regulam a produção do material onírico, estão a favor de uma explicação científica para os sonhos. Além desses dois elementos que compõem as regras que determinam a formação onírica, a resistência é outro mecanismo que tem forte influência no ato de sonhar.

A resistência concerne a um conflito de forças. Uma dessas forças se empenha para expressar algo, porém há uma força operando no sentido contrário para evitar sua expressão. Nesse jogo, quando uma das instâncias consegue efetuar seu desejo de expressar, a instância oposta acaba liberando a passagem para a consciência da ideia afetiva, no entanto; essa expressão é distorcida, sendo substituída por algo aceitável.

No caso dos sonhos, o inconsciente se esforça para expressar um conteúdo, mas como este não pode ser suportado pela consciência, sofre uma censura e é camuflado. Isso equivale a dizer que as instâncias em conflito entram em conciliação. Para sermos mais específicos, ocorre uma formação de compromisso, ou seja, o conteúdo recalcado acaba assumindo outra forma, diferente da original, para ser aceito no consciente, assim, nesse compromisso o desejo inconsciente acaba sendo satisfeito - ainda que de maneira distorcida - e as exigências defensivas também. Resumindo: 
FREUD E A TEORIA DA ELABORAÇÃO DOS SONHOS...

Num ponto, uma dessas forças pode ter conseguido efetuar o que quis dizer, ao passo que, em outro ponto, é a instância contrária que fez a comunicação pretendida eclipsar-se completamente, ou ser substituída por algo que não revela qualquer traço seu. Os casos mais comuns e mais característicos de construção onírica são aqueles nos quais o conflito terminou em uma conciliação, de forma tal que a instância com voz ativa certamente foi capaz de dizer o que quis, mas não da forma como quis apenas numa forma acentuada, distorcida, irreconhecível. (FREUD, 1996c, p. 24).

Para Freud o sonho é uma realização distorcida do desejo, afinal, o conteúdo inconsciente consegue se expressar, ainda que modo cifrado, alterado. Por trabalhar com conteúdos ocultos dos sonhos, a psicanálise não teria se distanciado de uma pretensão explicativa típica das ciências naturais? A resposta positiva equivale ao posicionamento de Ricoeur. Abaixo explanaremos sobre a natureza desta posição para, em seguida, contrastar com a posição de Heidegger.

\section{O OLHAR DE PAUL RICOEUR SOBRE A PSICANÁLISE DE FREUD}

Na obra Da interpretação: ensaio sobre Freud (1977), 
Ricoeur apresenta sua análise sobre o pensamento freudiano. Para o autor em comento, "de ponta a ponta, a psicanálise é interpretação” (RICOEUR, 1977, pág. 68). Ao abordar a psicanálise de Freud, Ricoeur a situa em afinidade com o estilo hermenêutico. Para o autor (1977, p. 32) não há um cânon universal para a exegese, assim, não temos um único conceito de hermenêutica capaz de suportar todas as ciências que versam sobre a interpretação; temos, então, estilos hermenêuticos; e a psicanálise de Freud estaria ao lado de uma hermenêutica da desmistificação. Esse estilo de interpretar preconiza uma transformação de signos em textos que serão consequentemente decifrados.

Essa forma de "traduzir" signos em textos não é de uso exclusivo de Freud, é uma metodologia presente no que Ricoeur alcunha de "escola da suspeita" (RICOEUR, 1977, p. 37). Nessa escola situam - se pensadores que, junto com Freud, seriam os mestres da suspeita: Marx e Nietzsche. Mas, em que consiste essa suspeita? Qual o ponto em comum entre esses três autores? Para responder essas indagações utilizaremos da seguinte passagem da supracitada obra:

Se remontarmos à sua intenção comum, descobriremos nela a decisão de considerar a consciência, em seu conjunto, como consciência "falsa". Retomam assim, cada um num registro 
FREUD E A TEORIA DA ELABORAÇÃO DOS SONHOS...

diferente, o problema da dúvida cartesiana, para transportá-la ao interior mesmo da fortaleza cartesiana. $O$ filósofo formado na escola de Descartes sabe que as coisas são duvidosas, que não são tais como aparecem. Mas não duvida de que a consciência não seja tal como ela aparece a si mesma: nela, sentido e consciência do sentido coincidem. Depois de Marx, Nietzsche e Freud, duvidamos disso. Após a dúvida sobre a coisa, ingressamos na dúvida sobre a consciência. (RICOEUR, 1977, p. 37)

Os três mestres comungam a dúvida sobre a consciência, além disso, esses três representantes da escola desmistificadora consideram a consciência como "falsa", portanto colocam sob suspeita a certeza cartesiana sobre a consciência. E qual a contribuição desses pensadores da escola da suspeita? Julgamos que a citação a seguir esclarece esse ponto:

Ora, todos três limpam o horizonte para uma palavra mais autêntica, para um novo reino da Verdade, não somente mediante uma crítica "destruidora", mas pela invenção de uma arte de interpretar. Descartes vence a dúvida sobre a coisa através da evidência da consciência. Eles vencem a dúvida sobre a consciência através de uma exegese 
do sentido. A partir deles a compreensão se torna uma hermenêutica: doravante procurar o sentido, não significa mais soletrar a consciência do sentido, mas decifrar suas expressões. (RICOEUR, 1977, p.38)

O exercício destes representantes de uma hermenêutica da suspeita é o da decifração, tendo como meta a compreensão de sentidos e não um posicionamento objetivo sobre o mundo ${ }^{7}$. Na concepção de Freud, a decifração está atrelada à busca dos sentidos ocultos dos sonhos e demais formações inconscientes, a exemplo do sintoma neurótico. Cabe perguntar, agora, como se dá o exercício da suspeita na ciência de Freud. De acordo com Sérgio Franco (1995, p. 108), a análise que Ricoeur faz da obra freudiana aponta para uma mudança no discurso psicanalítico, a qual vai fazer com que a interpretação ganhe um papel de destaque. No início das pesquisas freudianas, podemos, segundo Ricoeur, encontrar a marcante presença de um naturalismo, mas essa presença perde terreno ao longo das construções teóricas do pai da psicanálise. Nesse ponto é necessário indagar, como se deu esse processo? Para empreender esse esclarecimento, continuaremos nos servindo da obra Da Interpretação: Ensaio sobre Freud (1977) de Paul Ricoeur. O referido autor toma como ponto de partida o escrito freudiano Projeto para uma psicologia científica, no qual, acredita que há a presença de uma 
FREUD E A TEORIA DA ELABORAÇÃO DOS SONHOS...

abordagem quantitativa e neuronal. ${ }^{8} \mathrm{~A}$ forte presença de um mecanicismo é indicada por Monzani (1989, p.84) em sua descrição sobre a leitura de Ricoeur acerca do itinerário do pensar de Freud. Em A interpretação dos sonhos, Ricoeur reconhece a presença de uma virada no campo do discurso na medida em que a exegese de sentidos se sobrepõe à explicação energetista do funcionamento psíquico. ${ }^{9}$ Sobre esse modelo que oscila entre explicação e hermenêutica, Ricoeur faz a seguinte ponderação:

Os escritos de Freud se apresentam, de imediato, como um discurso misto, até mesmo ambíguo, que ora enuncia conflitos de força justificando uma energética, ora relações de sentido justificando uma hermenêutica. Gostaria de mostrar que essa ambiguidade aparente é bem fundada, que esse discurso misto é a razão de ser da psicanálise. (RICOEUR, 1977, p. 67).

No capítulo intitulado "Uma energética sem hermenêutica", Ricoeur (1977) dedica-se a explanações sobre o Projeto. A leitura que o francês faz desse escrito aponta para uma condição não hermenêutica da psicanálise, o que o faculta a considerá-lo como "[...] um estado não hermenêutico do sistema”. (RICOEUR, 1977, p. 69). Nos adverte Sérgio Franco (1995, p. 110) que esse estado 
hermenêutico corresponde à linguagem utilizada para seu desenvolvimento, posto que "o ambiente que o livro respira tem um caráter quase físico e um enfoque bem quantitativo" (FRANCO, 1995, p. 110). Nesse sentido, o comentador supracitado destaca a presença da formulação do princípio de constância, o qual Freud toma de empréstimo da física para estabelecer o mecanismo que rege o funcionamento do psiquismo humano. Segundo Franco:

O princípio de constância Freud o elabora a partir do princípio da inércia. $O$ princípio da inércia assevera que em um sistema fechado prevalece a tendência de reduzir as tensões internas a zero. Freud sofistica um pouco o conceito para estabelecer o princípio da constância: o sistema psíquico tende a manter tão baixo quanto possível o nível das tensões internas. (FRANCO, 1995, p. 110 - 111)

Com base na perspectiva ricoeuriana, no Projeto, Freud (1996b) teria ofertado ao leitor uma linguagem neurológica e pensado o aparelho psíquico em termos neurobiológicos. Monzani, em sua obra Freud $e$ o movimento de um pensamento (1989, p.82), argumenta que, para Ricoeur, o Projeto possui uma linguagem fisicalista e quantificável, uma vez que trata o psiquismo a partir de princípios mecânicos. Seguindo este horizonte de análise, 
FREUD E A TEORIA DA ELABORAÇÃO DOS SONHOS...

Garcia-Roza (1991, p.78) destaca que, já nas primeiras linhas desta obra, Freud afirma seu propósito em oferecer uma concepção quantitativa dos processos psíquicos. Visto que o pai da psicanálise se refere a neurônios e a circulação de energia entre eles, o texto é considerado por Ricoeur como um trabalho de neuropsicologia.

Ricoeur afirma, contudo, que, ao fim da obra em comento, Freud começa a empreender uma nova perspectiva de análise e abre caminhos para a articulação entre energética e hermenêutica. Nessa perspectiva, $o$ Projeto deixa brecha para a concepção de um aparelho que não tivesse a necessidade de comprovação anatômica, implicando no abandono das ideias de neurônios investidos. Ricoeur encerra o tópico do seu livro dedicado ao estudo da obra freudiana de 1895 afirmando que é preciso dar um passo a frente, pois “o 'Projeto' não é somente um sistema mecânico cortado da interpretação por sua hipótese anatômica; já é uma tópica, subterraneamente religada ao trabalho de decifração de sintomas" (RICOEUR, 1977, p.77). O que implica dizer que, nesse texto, já há uma incipiente possibilidade de hermenêutica.

$\mathrm{Na}$ medida em que começa a surgir uma hermenêutica na obra do pai da psicanálise, a perspectiva quantitativa é mitigada, o que faculta a Ricoeur sustentar a ideia de que a psicanálise não pode ser considerada apenas pelo seu legado energético, pois, mesmo no escrito mais 
neurológico acaba emergindo um discurso com teor interpretativo. Como nos afirma Franco, será após o Projeto que Freud introduzirá “(...) vários elementos na teoria, que são decifração e interpretação. Ele soma, assim, à sua visão energética elementos hermenêuticos." (FRANCO, 1995, p.112). Mas, devemos ressaltar que, aqui, ainda não há nenhuma supremacia da interpretação e sim um discreto surgimento; a explicação continuava como o cerne da teoria psicanalítica.

A ruptura em relação ao naturalismo e energetismo começa a ganhar, segundo Ricoeur, formas mais sólidas na obra A Interpretação dos sonhos uma vez que a análise e interpretação do sonho implicam em fornecer sentidos aos conteúdos distorcidos, implica decodificá-los. De acordo com o autor referido, "o difícil capítulo VII de $A$ Interpretação de sonhos (Traumdeutung) é, incontestavelmente, o herdeiro do "Projeto" de 1895" (RICOEUR, 1977, p. 83), isso quer dizer que ideias que estão presentes na $A$ Interpretação dos sonhos, estavam, mesmo que de forma implícita e incipiente, presentes no escrito O Projeto.

$\mathrm{O}$ autor francês argumenta que a explicação marcante nos escritos iniciais de Freud passa, a partir de 1900, a ser subordinada à interpretação, ou seja, a explicação que não dependia do analista e nem do paciente, e que anteriormente dominava a teoria psicanalítica, passou a 
FREUD E A TEORIA DA ELABORAÇÃO DOS SONHOS...

ocupar o segundo plano. Com A Interpretação dos sonhos, a explicação só se tornaria acessível através do trabalho de interpretação, sendo então; subordinada à exegese; sobre isso Ricoeur faz a seguinte reflexão:

Com A Interpretação de Sonhos a explicação sistemática é transferida para o fim de um trabalho efetivo cujas regras mesmas são elaboradas; e ela é expressamente destinada a transcrever graficamente o que se passa no "trabalho do sonho", que em si mesmo, só é acessível no e pelo trabalho da interpretação. Portanto, a explicação está explicitamente subordinada à interpretação. Não é por acaso que esse livro se chama Traumdeutung: $A$ Interpretação de Sonhos. (RICOEUR, 1977, p. 83)

O novo lugar que a interpretação passa a ocupar não é a única modificação destacada por Ricoeur em sua análise do itinerário do pensamento freudiano. $\mathrm{O}$ autor afirma que a psicanálise sofre algumas mudanças a partir da obra $A$ Interpretação dos sonhos. ${ }^{10} \mathrm{~A}$ primeira, como já foi mencionado anteriormente, foi ao lugar concedido à interpretação. A segunda alteração refere-se à transformação, ou melhor, à formulação de um aparelho psíquico sem referências anatômicas - daí o autor afirmar que "o aparelho psíquico de A Interpretação dos Sonhos 
funciona sem referência anatômica, é um aparelho psíquico" (RICOEUR, 1977, p. 83). Essa última alteração acarreta em outra mudança: diz respeito à representação real e a figurada. Ou seja, esse aparelho oscila entre as duas representações. Resumindo essas ideias de Ricoeur: com $A$ Interpretação dos sonhos Freud realiza uma transformação entre as relações tópico-econômicas e a interpretação que opera, o agora aparelho psíquico; não se fala mais em neurônios investidos e sim ideias investidas.

O entendimento de Ricoeur, segundo Franco (1995, p. 114), é que no sonho ocorre uma linguagem possível de ser interpretada e que a análise onírica revela a existência dos sentidos dos sonhos, os quais podem ser deslocados e distorcidos. A técnica consistiria em fazer com que o texto do sonho relatado seja “(...) substituído por outro texto mais claro, mais fácil de ser compreendido. A interpretação que faz essa operação [...] portanto, o sonho é signo com sentido e passível de interpretação" (FRANCO, 1995, p.114). Segundo Ricoeur (1977), quando o analista faz a decifração dos sentidos ocultos das manifestações inconscientes, está a exercer a desmitificação, afinal, destrona o lugar da consciência em favor da decodificação de signos cifrados oriundos do inconsciente.

Vale ressaltar que Ricoeur (1977, p.88) defende a existência de uma linguagem mista na obra freudiana sobre os sonhos. Para o autor, ainda que não tenha sido possível a 
FREUD E A TEORIA DA ELABORAÇÃO DOS SONHOS...

eliminação total do fator energético, não se pode enquadrar o discurso freudiano no rol dos discursos naturalizantes. Os componentes relativos ao campo da linguagem e os relativos à energética convivem de modo harmonioso, isso porque para o autor o sonho é um trabalho "que requer, para tematizar-se, uma linguagem mista que não seja nem puramente linguística, nem puramente energética". (RICOEUR, 1977, p. 88). Veremos logo abaixo que a posição heideggeriana se distancia desta apresentada pelo pensador francês.

\section{A PSICANÁLISE FREUDIANA À LUZ DA FILOSOFIA DE MARTIN HEIDEGGER}

Com o intuito de aproximar estudantes de medicina e psiquiatras dos estudos filosóficos, o psiquiatra Medard Boss convidou o filósofo, escritor e professor alemão Heidegger para ministrar aulas em Zollikon, na Suíça, onde lecionou por dez anos (1959-1969).”. De tal experiência resultou a obra Seminários de Zollikon. A referida produção contém palestras ministradas por Heidegger, e atas dos diálogos e cartas trocadas entre o psiquiatra Medard Boss e o filósofo. $\mathrm{O}$ objetivo desses seminários era trabalhar heranças filosóficas subjacentes às ciências que versam a respeito do homem, especificamente, sobre a saúde e o adoecimento psíquico. É na obra mencionada que nos 
deparamos com a crítica de Heidegger à psicanálise de Freud. De maneira sumária, podemos dizer que, para o filósofo alemão, Freud ergueu sua psicanálise sobre um solo cujo húmus histórico foi produzido pelas ciências naturais, portanto, pelo pensamento moderno e seu processo de objetificação do real. ${ }^{11}$

Para Heidegger, um dos conceitos cardeais da psicanálise, o de inconsciente, foi formulado no horizonte da pretensão de explicabilidade típica das ciências da natureza. Deteremo-nos a este tema porque o conceito de inconsciente se articula com o assunto de nosso artigo: a teoria freudiana da formação dos sonhos.

Ainda que tenha postulado um aparelho ficcional e não tenha pretendido comprovar sua realidade empírica em termos de anatomia cerebral, Freud não escapa, para Heidegger, da tentativa de objetificar e naturalizar o psiquismo. Para o filósofo, o pai da psicanálise advoga pela legitimidade do conceito de "inconsciente" na medida em que este está a serviço do determinismo, na medida em que cumpre a função de causa para todo ato psíquico: sonhos, atos falhos, chistes, sintomas. O que implica dizer, à luz dos argumentos heideggerianos, que o conceito de inconsciente não fere a tentativa científico-natural de tudo explicar, de apontar as causas e leis gerais. Heidegger afirma que Freud postulou o inconsciente para tornar explicáveis fenômenos 
FREUD E A TEORIA DA ELABORAÇÃO DOS SONHOS...

cujas motivações conscientes não eram suficientes para a elucidação. Em suas palavras:

Por não haver isto "na consciência" ele precisa inventar "o inconsciente", no qual tem de haver a ausência da lacuna de conexões causais. O postulado é a explicabilidade corrente do anímico, onde explicar e compreender são identificados. Este postulado não é tirado das próprias manifestações anímicas, mas ele é o postulado da ciência natural moderna. (HEIDEGGER, 2001, p. 260) [grifo nosso]

$\mathrm{O}$ estabelecimento de leis que regem o psiquismo e o estabelecimento do inconsciente como fator causal de sintomas, sonhos e outros fenômenos humanos confirmam, para Heidegger, que o tratamento dado ao homem; por Freud, afina-se com a identidade científico-natural. Afinidade essa, assumida pelo pai da psicanálise; ao afirmar que "também a psicologia é uma ciência natural. $\mathrm{O}$ que mais pode ser?" (FREUD, 1996e, p.298) ${ }^{12}$

Ainda que Freud fale de decifração de sonhos e de interpretação de sintomas, não há, na perspectiva heideggeriana, uma ruptura com as pretensões de explicabilidade cativas à postura científico-natural. Isso porque a apropriação interpretativa está subjugada à 
pretensão de explicação e determinação objetiva dos elementos causais. A tentativa freudiana de explicar o psiquismo humano, denunciada por Heidegger, pode ser detectada em uma passagem de sua obra tardia Esboço de Psicanálise. Freud diz que:

Enquanto a psicologia da consciência nunca foi além "das sequências rompidas" a outra visão, que sustenta que o psíquico é inconsciente em si mesmo, capacitou a Psicologia a assumir seu lugar entre as ciências naturais, como ciência. Os processos em que está interessada são, em si próprios, tão incognoscíveis quanto aqueles que tratam as outras ciências, a Química ou a Física, por exemplo; mas é possível estabelecer as leis a que obedecem" (FREUD, 1996d, p.172)[grifo nosso]

Da citação acima podemos depreender que, para Freud, foi a partir da sistematização do conceito de inconsciente que a psicanálise alçou estatuto de ciência, de ciência natural, tal como a física e a química. Assoun, em sua obra Introdução à epistemologia freudiana (1983, p. 66), diz que toda vez que Freud pretende caracterizar sua ciência faz comparação com as ciências mais duras; o autor assegura, ainda, que Freud não escolhe a ciência natural em detrimento da ciência do espírito, posto que, simplesmente 
FREUD E A TEORIA DA ELABORAÇÃO DOS SONHOS...

ignora outra forma de se fazer ciência que não seja a ciência natural. Sobre essa identidade epistêmica da psicanálise, Assoun afirma:

Ora, eis por onde se anuncia a singularidade freudiana; Por sua obstinação um pouco teimosa em rotular sua psicanálise de Naturwissenschaft, encontra o meio de escamotear a questão, de ignorála placidamente. Não escolhe a ciência da natureza contra uma ciência do espírito; quer mostrar praticamente, que a alternativa não existe, na medida em que, em fato de cientificidade, só pode tratar-se de ciência da natureza. Freud, na aparência, não conhece outra forma de ciência. (ASSOUN, 1983, p.48) [itálico do autor]

Essa filiação da psicanálise freudiana com as ciências naturais tem no inconsciente seu elo fundamental, uma vez que sua função é, segundo Loparic (1991, p. 51), é "fornecer explicações dinâmicas (causais) da existência dos sintomas", o que implica dizer que tal conceito está a serviço de uma explicabilidade que se distancia da proposta de compreensão de fenômenos típica das ciências do espírito. ${ }^{13}$ Nessa perspectiva, podemos dizer que o inconsciente é uma formulação da ordem da especulação que serve para dar inteligibilidade aos sonhos, sintomas, atos falhos, atos sintomáticos, etc. Os conceitos especulativos, segundo 
Fulgencio, têm como objetivo " $[. .$.$] completar as teorias$ empíricas, tornando possível melhor agrupar e ordenar os fatos clínicos, fornecendo um guia tanto para a procura de explicações quanto para obter novos dados" (FULGENCIO, 2003, p. 146). Ao criar e fazer o uso desse conceito, Freud se serve de um tipo de procedimento metodológico que é muito usado pela física aquele que se vale de convenções e analogias para ordenar dados observáveis. Um exemplo de uma convenção frutífera para a física é o conceito de força. Não é possível encontrar empiricamente tal constructo, mas isso não abala a estrutura científica da física. ${ }^{14}$

Fulgencio nos lembra ainda que, "para explicar um determinado fenômeno ou movimento na natureza, é preciso fornecer a série completa de determinações causais que o produziu" (FULGENCIO, 2008, p. 77). Essa determinação é produzida pelo inconsciente freudiano, posto que se trata do elemento formador dos fenômenos psíquicos, inclusive os sonhos. Em função disso, Heidegger nos fala que, este conceito e suas derivações não representam uma ruptura com o naturalismo, ao contrário, confirmam a afinidade da psicanálise freudiana com a identidade epistemológica com as ciências naturais. A análise freudiana dos sonhos, na perspectiva heideggeriana, seria mais uma formulação teórica a serviço da explicabilidade do psiquismo; ainda que Freud postule uma interpretação e decifração do material onírico, faz tal 
FREUD E A TEORIA DA ELABORAÇÃO DOS SONHOS...

postulado ancorado na pretensão de detectar o fator causal que atua na formação do sonho. Isso implica, para Heidegger, em destinar aos fenômenos humanos pretensões explicativas típicas das ciências da natureza.

\section{CONSIDERAÇÕES FINAIS}

Se Freud, ao definir seu campo de saber, atesta que a psicanálise é uma ciência natural, e este tipo de ciência visa explicar o fenômeno estabelecendo leis gerais, qual seria então o papel da interpretação na psicanálise freudiana? Seria possível uma junção entre a parte explicativa e uma interpretativa? Seria possível dizer que, com a decifração dos sonhos, temos uma soberania dos elementos interpretativos sobre os explicativos?

Segundo Ricoeur (1977), quando o analista faz uma interpretação das manifestações inconscientes exerce uma desmitificação, posto que decifra os códigos cifrados desses conteúdos. Para o pensador francês, Freud teria substituído a linguagem explicativa por uma linguagem de compreensão dos sentidos. Como nos lembra Monzani, para Ricoeur "a explicação está, portanto, explicitamente subordinada à interpretação" (MONZANI,1989, p. 85).

Assoun (1983, p. 49), no entanto- nos indica que ao interpretar, Freud busca causas geradoras de determinado 
fenômeno psíquico, ou seja, as associações de sentido que são tecidas em análise estão subordinadas à necessidade de sua explicação causal. Para o comentador, "nunca o genial 'senso clínico' de Freud transgride seu imperativo explicativo" (ASSOUN, 1983, p.50). Essa assertiva de Assoun afina-se com os argumentos de Loparic. Este último pesquisador, assim como o primeiro, argumenta que as interpretações psicanalíticas são em prol da explicação causal dos acontecimentos. Deste modo, “(...) em Freud, toda compreensão é, ao mesmo tempo, explicação: o que se compreende e interpreta é a causa de um sintoma" (LOPARIC, 2001, p.263). Os argumentos dos autores mencionados acima coadunam com o do estudioso da psicanálise Renato Mezan. Ao abordar a técnica psicanalítica de interpretação dos sonhos, em seu texto "Que tipo de ciência é, afinal, a psicanálise?", Mezan afirma que:

Interpretar um sonho é encontrar o seu sentido - o desejo inconsciente e as fantasias em que ele se incorpora. Mas esse desejo é igualmente uma das causas daquele sonho, sendo a outra a "potência psíquica” que se opõe à realização dele (responsável pela censura). Ao elucidar o sentido, a interpretação revela também as causas, tanto materiais (o desejo inconsciente) quanto formais (as operações do 
FREUD E A TEORIA DA ELABORAÇÃO DOS SONHOS...

processo primário que incidiram sobre o material original). O mesmo vale para as "tendências" cujo choque produz o ato falho, a piada ou o sintoma neurótico: aquilo que aparece na consciência. (MEZAN, 2007, p. 334)

Para Heidegger, ao postular o inconsciente, Freud não fere a tentativa de tudo explicar, de criar leis e operar com elas, assim como faz as demais ciências naturais. Nessa perspectiva, ao supor a existência de uma instância psíquica inconsciente formadora dos sonhos, Freud visa a explicabilidade destes conteúdos psíquicos. A necessidade de criação de leis que regem o psíquico, assim como o estabelecimento do inconsciente como elemento formador de todos os acontecimentos psíquicos, confirma, para Heidegger, que o tratamento dispensado ao homem por Freud afina-se com a identidade científico-natural. Como diz Garcia-Roza (1991, p. 76), o criador da psicanálise tem uma "crença inabalável de que os processos psíquicos são passíveis de serem expressos por leis científicas".

O posicionamento de Heidegger é bem distinto da avaliação de Ricoeur. Parece que este último não considerou que a interpretação realizada por Freud na clínica está interessada em “(...) reconstituir a objetividade das associações oníricas”, está interessada em apontar as causas envolvidas na produção do sonho (ASSOUN, 1983, p.50). 
Uma vez que o conceito de inconsciente está a serviço do imperativo da explicabilidade de conexões causais - e o sonho é um produto do inconsciente - Heidegger (2001) enquadrou o saber de Freud no rol das ciências da natureza e lançou dúvidas sobre a suposta ruptura deste autor em relação à modernidade. Para preencher as lacunas existentes na psicologia da consciência, Freud postulou o inconsciente e estabeleceu as leis que regem o psiquismo.

A partir do exposto somos convencidos acerca da dificuldade de sustentar o que advoga Ricoeur, a saber, que o energetismo cedeu um vasto lugar para os elementos hermenêuticos na teoria freudiana da interpretação dos sonhos. À luz de Heidegger e de comentadores da psicanálise somos levados a concluir que o conceito de inconsciente e a formulação acerca da formação onírica são responsáveis por uma aproximação da psicanálise freudiana com a identidade científico-natural.

\section{NOTAS}

${ }^{1}$ Graduanda em Psicologia pela Universidade Estadual de Feira de Santana (UEFS). E-mail: fernanda.uefs2011@hotmail.com. Este texto é fruto de uma pesquisa de iniciação científica financiada pelo $\mathrm{CNPq}$ no período de 2015-2016. 
FREUD E A TEORIA DA ELABORAÇÃO DOS SONHOS...

${ }^{2}$ Professora Titular de Filosofia pela Universidade Estadual de Feira de Santana (UEFS). Doutora em Filosofia pela Universidade Estadual de Campinas (UNICAMP) E-mail: carolinevasconcelos@hotmail.com.

${ }^{3}$ Para Ricoeur (1977), Freud iniciou suas pesquisas sob a égide da neurologia e do naturalismo, pensando o psiquismo a partir da relação entre neurônios. Com $A$ interpretação dos Sonhos, a máquina psíquica passou a ser fictícia e não neuronal e anatômica. Em função disso, Ricoeur indica que a influência do naturalismo foi perdendo força na teoria freudiana.

${ }^{4}$ Como exemplo de conceitos que não têm base na empiria, mas têm valor heurístico para explicar fenômenos empíricos, mencionamos os conceitos de aparelho psíquico, inconsciente, pulsão, dentre outros de natureza metapsicológica. Segundo Fulgencio (2003, p. 140) um conceito desta natureza “(...) tem validade pelo que torna possível compreender sobre os fenômenos e suas relações, e não em si mesmo”.

${ }^{5}$ Restringiremos-nos a analisar a primeira tópica do aparelho psíquico porque é com esta formulação que Freud sistematiza sua concepção sobre a formação onírica. Nos anos 20 há um remodelamento da topografia do aparelho e o estabelecimento de uma segunda tópica, cujas instâncias passam a ser o Id, o Ego e o Superego. Em Esboço de psicanálise, Freud (1996d, p.158) resume a relação entre estes sistemas da seguinte maneira: os conteúdos inconscientes habitam o reservatório das pulsões no aparelho - o Id. Sob a influência do mundo externo uma porção do Id se organiza e é denominada de Ego, instância que se esforça pela busca do prazer e fuga do desprazer. Portanto, cabe ao Ego atuar como intermediário entre o Id e o mundo externo. Ao longo período da infância se forma uma outra instância no aparelho, o Superego cuja tarefa consiste “ (...) em ser um agente especial no qual se prolonga a influência parental” (FREUD, 1996d, p.159).

6 De maneira sumária, encontramos a definição de censura no Vocabulário da psicanálise, da seguinte maneira: "função que tende a 
interditar aos desejos inconscientes e às formações que deles derivam o acesso ao sistema pré-consciente-consciente". (LAPLANCHE e PONTALIS, 2008, p. 64).

7 Freud, Marx e Nietzsche - de diferentes modos, mas com "um parentesco subterrâneo" - são, para Ricoeur, mestres da suspeita por instaurarem uma crítica à consciência e pela invenção de uma arte de interpretar. Segundo Ricoeur (1977), Descartes vence a dúvida sobre a coisa através da evidência da consciência e os três, em contrapartida, vencem a dúvida sobre a consciência através da exegese de sentidos. Enquanto Marx encaminhou sua suspeita para o campo da alienação econômica e Nietzsche para o da vontade de poder, Freud ingressou na crítica à consciência falsa por uma dupla entrada: o sonho e o sintoma neurótico. Cf.: Ribeiro, 2014.

${ }^{8}$ Doravante nos referiremos a essa obra como Projeto.

${ }^{9}$ Ricoeur, ao falar do traço energetista do discurso freudiano, refere-se às análises que versam sobre a carga e descarga de energias atreladas aos conflitos. Esse componente do discurso freudiano teria uma afinidade maior com as quantificações e explicações objetivas do que com a exegese de sentido. Cf.: Ricoeur, 1977

${ }^{10}$ Segundo Monzani (1989, p.87), para Ricoeur a obra sobre os sonhos é carregada de um discurso misto, que mescla a linguagem física da tópica e a linguagem do sentido, que provém da interpretação. Os escritos de metapsicologia representam, para Ricoeur (1977, p.105), a maturidade da problemática entre os dois aspectos do discurso psicanalítico. Nesses escritos, Freud teria alcançado o ponto de equilíbrio entre força e sentido. Para provar isso, Ricoeur procede a uma análise do conceito metapsicológico fundamental: pulsão. Cf. Monzani, 1989 e Ricoeur, 1977.

${ }^{11}$ Segundo Ribeiro (2008) esse processo consiste em fazer de qualquer coisa objeto, subordinar o advento da totalidade dos entes ao domínio 
FREUD E A TEORIA DA ELABORAÇÃO DOS SONHOS...

objetivo. O que implica dizer que nada pode advir, vir à luz que não seja determinado como objeto de apreensão rigorosa. Cf. Ribeiro, 2008 12 Sobre a declarada pretensão freudiana de ser reconhecido como cientista da natureza conferir: Assoun, 1983, Fulgencio, 2003 e Ribeiro, 2008.

${ }^{13}$ Estamos aqui nos referindo ao que ficou conhecido como querela dos métodos. Essa querela diz respeito a duas pretensões de apreensão que são bastante distintas, a saber, o Explicar (erklären) e o Compreender (verstehen). A ciência da natureza busca explicar os fatos estabelecendo leis e princípios causais, as ciências do espírito, em contrapartida, visam compreender os sentidos dos fenômenos. Como nos indica Assoun "as ciências da natureza se atêm aos juízos de realidade, enquanto que as ciências do espírito implicam a valorização". (ASSOUN, 1983, p. 47) ${ }^{14}$ Uma vez que as convenções não podem ser preenchidas por uma matéria sensível, resta ao pesquisador nelas projetar, de forma analógica, propriedades relativas ao campo empírico. Fulgencio nos ilustra essa operação com o conceito de força na física; para o autor "É assim, por exemplo, que o conceito de força, que é apenas uma ideia sem correspondente (referente) empírico, é tomado como se tivesse uma realidade análoga à da pressão que sentimos quando algo toca nosso corpo ou quando colocamos o nosso corpo em movimento". (FULGENCIO, 2008, p.368). 


\section{REFERÊNCIAS BIBLIOGRÁFICAS}

ASSOUN, P-L. Introdução à epistemologia freudiana. Tradução: Hilton Japiassu. Rio de Janeiro: imago, 1983.

FRANCO, Sérgio de Gouvêa. Hermenêutica e Psicanálise na obra de Paul Ricoeur. São Paulo: Loyola, 1995.

FREUD, S. "A Interpretação dos sonhos". In Edição Standard brasileira das obras completas de Sigmund Freud. Rio de Janeiro: Imago Editora, 1996a. Vol. V.

FREUD, S. "Algumas lições elementares de psicanálise”. In: Edição Standard brasileira das obras completas de Sigmund Freud. Rio de Janeiro: Imago Editora, 1996e. Vol. XXIII.

FREUD, S. "Alguns Comentários sobre o Conceito de Inconsciente na Psicanálise". In: Obras completas de Sigmund Freud. Tradução de Luiz Alberto Hanns. - Rio de Janeiro: Imago Editora. Vol. I, pp.79 - 93, 2004.

FREUD, S. "Esboço de psicanálise". In: Edição Standard brasileira das obras completas de Sigmund Freud. Rio de Janeiro: Imago Editora, 1996d. Vol. XXIII.

FREUD, S. "Novas conferências introdutórias sobre a psicanálise. Conferência XXIX: Revisão da teoria dos sonhos". In: Edição Standard brasileira das obras completas de Sigmund Freud. Rio de Janeiro: Imago Editora, 1996c. Vol. XXII. 
FREUD E A TEORIA DA ELABORAÇÃO DOS SONHOS...

FREUD, S. "Projeto para uma psicologia científica". In: Edição Standard brasileira das obras completas de Sigmund Freud. Rio de Janeiro: Imago Editora, 1996b. Vol. I.

FULGENCIO, L. "As especulações metapsicológicas de Freud" in: Natureza Humana - Revista Internacional de Filosofia e Psicanálise. São Paulo: EDUC, vol. 5.n 1, 2003.

FULGENCIO, L. O método especulativo em Freud. São Paulo: EDUC, 2008.

GARCIA-ROZA, L. Introdução à metapsicologia freudiana, v.1. Sobre as afasias (1891): O projeto de 1895. Rio de Janeiro: Jorge Zahar Ed., 1991.

HEIDEGGER, M. Seminários de Zollikon. Tradução brasileira: Maria de Fátima Almeida Prado, Gabriela Arnhold, São Paulo: EDUC; Petrópolis: Vozes, 2001.

LAPLANCHE, J. \& PONTALIS, J.B. Vocabulário de Psicanálise. Tradução: Pedro Tamen. São Paulo: Martins Fontes, 2008.

LOPARIC, Z. "Além do Inconsciente - sobre a desconstrução heideggeriana da psicanálise". In: Natureza Humana - Revista Internacional de Filosofia e Psicanálise. São Paulo: EDUC, vol. 3.n 1, pp. 91-140, 2001.

LOPARIC, Z. "Um olhar epistemológico sobre o inconsciente freudiano" In: Knobloch, F. (org.) O 
inconsciente: várias leituras. São Paulo: Editora Escuta, 1991.

MEZAN, R. “Que tipo de ciência é, afinal, a psicanálise?" In: Natureza - Revista Internacional de Filosofia e Psicanálise. São Paulo: EDUC, vol. 9, nº 2, 2007.

MONZANI, L, R. "A máquina de sonhar". In: Freud: o movimento de um pensamento. Campinas: Editora Unicamp, 1989.

RIBEIRO, C. V. "Freud se encaixaria no rol dos operários (Handwerker) das ciências naturais? Considerações heideggerianas acerca da psicanálise freudiana". In: Aprender: Caderno de Filosofia e Psicologia da Educação. Vitória da Conquista: Edições UESB, v. 10, 2008.

RIBEIRO, C.V. "Freud e o Methodenstreit: um debate a partir dos Seminários de Zollikon" in: Diálogos Possíveis. Salvador: vol13, n.2, 2014

RICOEUR, P. Da interpretação: ensaio sobre Freud. Rio de Janeiro: Imago Editora, 1977. 